九州大学学術情報リポジトリ

Kyushu University Institutional Repository

Clinical disability progression and platelet GP IIb/IIIa values in patients with atopic myelitis

グリバハルアアィィディン

ht tps://doi. org/10.15017/1441115

出版情報：九州大学，2013，博士（医学），課程博士 バージョン：

権利関係：やむを得ない事由により本文ファイル非公開（2） 


\section{Clinical disability progression and platelet GP IIb/IIIa values in patients with atopic myelitis}

Gulibahaer Ainiding ${ }^{\mathrm{a}}$, Ken-ichiro Yamashita ${ }^{\mathrm{a}}$, Takako Torii ${ }^{\mathrm{a}}$, Kounosuke Furuta ${ }^{\mathrm{a}}$, Noriko Isobe $^{\mathrm{a}}$, Takuya Matsushita ${ }^{\mathrm{b}}$, Katsuhisa Masaki ${ }^{\mathrm{a}}$, Shoji Matsumoto ${ }^{\mathrm{c}}$, Jun-ichi Kira ${ }^{1, *}$

aDepartment of Neurology, Neurological Institute, Graduate School of Medical Sciences, Kyushu University, Fukuoka, Japan

${ }^{b}$ Department of Clinical Neuroimmunology, Graduate School of Medical Sciences, Kyushu University, Fukuoka, Japan

'Department of Neurology, Saiseikai General Hospital, Fukuoka, Japan

*Corresponding author: Jun-ichi Kira, Department of Neurology, Kyushu University, 3-1-1

Maidashi, Higashi-ku, Fukuoka 812-8582, Japan

Phone: $+81-92-642-5340$

Fax: $+81-92-642-5352$

E-mail: kira@neuro.med.kyushu-u.ac.jp

Character count for the title: $\quad 97$ characters (including spaces)

Word count for the abstract: $\quad 97$ words

Word count for the text: $\quad 2,194$ words

Numbers of tables and figures: $\quad 1$ table and 1 figure 


\section{ABSTRACT}

We aimed to clarify the disability progression and platelet aggregative function in atopic myelitis (AM). Seventeen AM patients and 35 healthy controls were subjected to clinico-allergological evaluations and GP IIb/IIIa measurements using a VerifyNow assay system. In AM patients, the disease duration had significant positive correlations with the Kurtzke Expanded Disability Status Scale scores and Sensory Functional Scale scores. The GP IIb/IIIa values were significantly higher in AM patients than in controls as well as in females compared with males. AM is essentially a progressive disease affecting the sensory system, and involves an increased platelet aggregative function.

Key words: myelitis; atopy; progression; platelet; GP IIb/IIIa; aggregation 


\section{Introduction}

We first reported the emergence of myelitis in patients with atopic disorders, and named it atopic myelitis (AM) (Kira et al., 1997; Kira et al., 1998; Kira et al., 1999; Kira et al., 2001). Repeated nationwide surveys of this condition have revealed a widespread occurrence of AM in Japan (Osoegawa et al., 2003a; Isobe et al., 2009). Similar cases have recently been reported in Europe (Zoli et al., 2005; Constantinescu et al., 2006), including a biopsy-proven case showing marked eosinophil infiltration (Gregoire et al., 2006), as well as in East Asia including a relatively large series from Korea (Yoon et al., 2009). In AM patients, we found that CCL2, a chemokine for eosinophils, and interleukin-9, a T helper 2 (Th2) cytokine, were both markedly upregulated in the cerebrospinal fluid, and that the levels of these molecules showed strong positive correlations with the disease severity (Tanaka et al., 2008), collectively suggesting that atopy-related inflammation is operative. A histological study of biopsied spinal cord specimens revealed eosinophilic inflammation and simultaneous loss of both axons and myelin (Kikuchi et al., 2001; Osoegawa et al., 2003b). The condition showed a poor response to corticosteroids but responded to plasma exchanges (Murai et al., 2004). However, the disability progression over the clinical course is still ill-defined.

A recent nationwide survey investigating both AM and atopy-related peripheral neuritis (APN), such as Churg-Strauss syndrome (CSS), revealed a considerable overlap between AM and APN (Isobe et al., 2009). In CSS, ischemia of peripheral nerves caused by inflammation is supposed to be the dominant mechanism for neural damage, and even the optic nerve is affected by the ischemic process in this condition (Liou et al., 1994; Giorgi et al., 1997). Atopic disorders have been reported to be associated with cardiovascular diseases (Brunekreef et al., 2000), and platelet activation in allergy is assumed to play a significant 
role in these situations (Masini et al., 1994). Platelet aggregation is mediated by interactions of fibrinogen with glycoprotein receptors on platelets, such as GP IIb/IIIa ( $\alpha \operatorname{IIb} \beta 3$ integrin), which is the central receptor for platelet aggregation (Kasperska-Zajac and Rogala, 2007; Pitchford, 2007). Therefore, in the present study, we aimed first to clarify the relationship between the disease duration and disability progression in AM, and second to reveal any platelet aggregative function abnormalities by measuring the GP IIb/IIIa contents.

\section{Subjects and methods}

\subsection{Subjects and clinico-allergological evaluation}

AM was defined as myelitis of unknown cause with either (1) hyperIgEemia ( $>240$ $\mathrm{U} / \mathrm{ml}$ ) and antigen-specific IgE positivity or (2) coexistent or past atopic diseases following the diagnostic criteria, excluding other diseases (Osoegawa et al., 2003a). Bronchial asthma, atopic dermatitis, allergic rhinitis, food allergy and allergic conjunctivitis were regarded as atopic diseases in the present study. The existence of myelitis was confirmed by spinal cord MRI, motor-evoked potentials, somatosensory-evoked potentials or neurological findings of either exaggerated deep tendon reflexes or sensory levels. Detailed clinical information on individual patients, including symptomatology, disability scores including the Kurtzke Expanded Disability Status Scale (EDSS) score (Kurztke, 1983), Pyramidal Functional Scale (FS) score (Kurztke, 1983) and Sensory FS score (Kurztke, 1983), Progression Index (Sanders et al., 1986; Chapman et al., 2001), and allergological, neuroimaging and electrophysiological data, were retrospectively evaluated. All 17 AM patients who visited the Department of Neurology, Kyushu University Hospital, from 1 March 2010 to 31 May 2011 were enrolled in the present study. These AM patients comprised 6 males and 11 females, with a mean $( \pm S D)$ age at examination of $43.4 \pm 13.2$ years, mean age at onset of $36.3 \pm 12.2$ 
years and disease duration of $7.0 \pm 5.0$ years. In addition, 35 healthy controls with no medication were evaluated in this study. The control subjects comprised 16 males and 19 females, with a mean age at examination of $31.6 \pm 4.8$ years. The sex ratios did not differ significantly between the two groups, while the age at examination was significantly higher in the AM patients than in the controls $(\mathrm{p}<0.01)$. All the AM patients and controls were subjected to a questionnaire survey for past and present history of the above-mentioned atopic diseases, and underwent routine laboratory tests including blood cell counts (white blood cells, platelets, eosinophils, neutrophils and lymphocytes), hemoglobin, total IgE and common allergen-specific IgE. This study was approved by the ethical committee of Kyushu University Hospital. Written informed consent was obtained from all subjects.

\subsection{Measurement of GP IIb/IIIa}

GP IIb/IIIa was assayed as an index of platelet aggregative function using a VerifyNow GP IIb/IIIa assay system (Accumetrics, San Diego, CA; Van Werkum et al., 2008). This spectrophotometric assay system is comparable to other well-established methods for platelet aggregation and produces rapid results with small amounts of whole blood (Matzdorff et al., 2001; Wheeler et al., 2002; White et al., 2004). Fresh venous blood was drawn from the patients and healthy controls, who had received no medications affecting platelet aggregation at least for 1 week prior to the blood drawing, and immediately subjected to the assay according to the manufacturer's recommendations (Accumetrics; Michelson, 2009). The results were expressed as platelet aggregation units (PAU).

\subsection{Statistical analysis}

First, we examined whether all of the clinical and laboratory data showed normal 
distributions. Student's $t$-test and Welch's test were used to compare the significance of differences between the laboratory and demographic features between the AM patients and controls. When comparing the frequencies of atopic disorders between the AM patients and controls, Fisher's exact probability test was used. Since the GP IIb/IIIa values showed a normal distribution in the subjects, a two-way ANOVA was used to compare the GP IIb/IIIa values by sex and disease. Pearson's $r$ correlation test was used to measure the degrees of the relationships between the GP IIb/IIIa values and clinical and laboratory parameters. The level of statistical significance was set at $\mathrm{p}<0.05$. All analyses were performed using SPSS software (SPSS Inc., Chicago, IL).

\section{Results}

\subsection{Demographic features of the AM patients}

The AM patients showed EDSS scores of $3.2 \pm 1.8$ (mean \pm SD), Pyramidal FS scores of $2.2 \pm 1.3$, Sensory FS scores of $1.9 \pm 1.5$ and Progression Indexes of $1.3 \pm 1.7$. The disease duration showed significant positive correlations with the EDSS scores $(\mathrm{r}=0.61$, $\mathrm{p}<0.01)$ and Sensory FS scores $(\mathrm{r}=0.64, \mathrm{p}<0.01)$, but not the Pyramidal FS scores (Fig. 1A, B). There were no sex differences in any of the clinical parameters (data not shown).

\subsection{Comparisons of hematological and allergological findings between the AM patients and} healthy controls

Compared with the controls, the AM patients had significantly higher frequencies of bronchial asthma $(p<0.001)$, allergic rhinitis $(p<0.05)$, food allergy $(p<0.05)$ and allergic conjunctivitis $(\mathrm{p}<0.05)$ (Table 1). The IgE levels and neutrophil counts were significantly higher in the AM patients than in the controls ( $p<0.05$ for both). The allergen-specific IgE 
levels did not differ significantly between the AM patients and controls in the present study, including those against Dermatophagoides pteronyssinus and Dermatophagoides farina, probably reflecting the small simple size. There were no other significant differences in the routine hematological tests between the two groups. The hemoglobin levels were significantly higher in males than in females $(14.9 \pm 1.1$ vs. $12.7 \pm 1.1 \mathrm{~g} / \mathrm{dl}, \mathrm{p}<0.01$ for all subjects).

\subsection{GP IIb/IIIa values and their relationships with clinical parameters}

The GP IIb/IIIa values tended to be higher in the AM patients (mean $\pm \mathrm{SD}$ : $224.8 \pm 44.1)$ than in the healthy controls $(201.9 \pm 29.5)$ as a whole group $(p=0.06)$. Considering the sex differences as a secondary factor affecting the GP IIb/IIIa differences between the two groups, we performed a two-way ANOVA for further analysis (Fig. 1C). The two-way ANOVA of the GP IIb/IIIa values by sex and disease revealed significant main effects for $\operatorname{sex}(F[1,51]=22.56, p<0.01)$ and disease $(F[1,51]=4.69, p<0.05)$. There was no sex-by-disease interaction. Thus, the GP IIb/IIIa values were significantly higher in females than in males in both the AM patients and controls, and were also significantly greater in the AM patients than in the controls.

\subsection{Correlations between the GP IIb/IIIa values and clinical parameters}

In the AM patients, the GP IIb/IIIa values showed a significant positive correlation with the platelet counts $(r=0.57, \mathrm{p}<0.05)$ (Fig. 1D). In contrast, there was no correlation between the GP IIb/IIIa values and the platelet counts in the controls. In addition, the GP IIb/IIIa values had a tendency to show a mild negative correlation with the hemoglobin concentrations $(\mathrm{r}=-0.48, \mathrm{p}=0.05)$ in the AM patients, while there was a significant negative 
correlation between the GP IIb/IIIa values and the hemoglobin concentrations in the controls $(r=-0.64, p<0.01)($ Fig. 1E). No correlations of the GP IIb/IIIa values were found with the other clinical and laboratory parameters, including age at onset, age at examination, EDSS scores, Pyramidal FS scores, Sensory FS scores, disease duration, Progression Indexes, white blood cell counts, eosinophil counts, neutrophil counts, and total and allergen-specific IgE levels.

\section{Discussion}

The main new findings of the present study are as follows: (1) in AM patients, the disease duration had significant positive correlations with the EDSS scores and Sensory FS scores but not the Pyramidal FS scores; (2) the GP IIb/IIIa values were significantly higher in the AM patients than in the controls, as well as in females compared with males; and (3) the GP IIb/IIIa levels showed a significant positive correlation with the platelet counts in the AM patients but not in the controls.

AM patients predominantly present a fluctuating course of paresthesia/dysesthesia in the distal parts of all four limbs (Osoegawa et al., 2003a; Isobe et al., 2009). The present study has revealed for the first time a positive correlation of the disease duration with the EDSS scores in AM patients, suggesting that AM is essentially a progressive disease in most patients, although superimposed fluctuations of the symptoms may occur (Osoegawa et al., 2003a; Isobe et al., 2009). The disease preferentially affects the posterior column of the spinal cord radiologically as well as pathologically, which is in accord with the positive correlation of the disease duration with the Sensory FS scores but not the Pyramidal FS scores. Thus, the disability of AM patients over the clinical course is considered to be determined by the posterior column sensory impairment. 
The GP IIb/IIIa values had a significant negative correlation with the hemoglobin levels in the controls and showed a tendency toward a negative correlation with the hemoglobin levels in the AM patients. This may be explained by the methodological reason that the VerifyNow system is a kind of turbidity assay, which leads us to a cautious interpretation of the results. The lower GP IIb/IIIa levels in males compared with females may partly reflect the higher hemoglobin levels in males than in females, because higher hemoglobin amounts reduce the absorbance, thereby lowering the GPIIb/IIIa levels in the present assay. However, Faraday et al. (1997) reported that a higher proportion of GP IIb/IIIa was activated in females compared with males, suggesting that the elevated GP IIb/IIIa levels in females may represent a physiological sex difference in platelet activity. In the present study, however, the hemoglobin levels did not differ significantly between the AM patients and controls. Furthermore, although the age at examination was higher in the AM patients than in the controls, the GP IIb/IIIa values had no correlation with the age at examination. Thus, the elevated GP IIb/IIIa levels in the AM patients are supposed to be real rather than artifacts.

Activated GP IIb/IIIa binds to fibrinogen or von Willebrand factor, thereby forming molecular bridges between aggregating platelets, and an increased amount of GP IIb/IIIa is associated with a higher platelet aggregation function (Yakushkin et al., 2011). Therefore, the increased GP IIb/IIIa amounts in the AM patients suggest a possible exaggerated reactivity of platelets in this condition in vivo. Atopy-related neural disorders, in which microcirculatory disturbance is assumed, are not only limited to CSS, but may also exist in several other neurological conditions associated with atopic diathesis, such as juvenile muscular atrophy of the distal upper limb (Hiramaya disease) (Hirayama et al., 1959) and Hopkins syndrome (Hopkins, 1974). We (Kira and Ochi, 2001) and others (Ito et al., 2005) 
reported an association of atopic diathesis with Hirayama disease, in which shrinkage and necrosis of the anterior horns of the cervical spinal cord were noted at autopsy (Hirayama et al., 1987). Another rare disease is an acute poliomyelitis-like illness known as Hopkins syndrome (asthmatic amyotrophy). The disease presents as sudden onset of flaccid paralysis following asthma attacks in children (Ito et al., 2005), and responds poorly to corticosteroids in most cases (Shahar et al., 1991). We also reported cases of AM showing focal amyotrophy and anterior horn cell involvement (Tokunaga et al., 2004; Kira et al., 2008), suggesting possible links of AM with Hopkins syndrome and Hirayama disease (Kira et al., 2008). In Hirayama disease, repeated microcirculatory disturbances are assumed to cause anterior horn cell necrosis, which is vulnerable to ischemia (Hirayama, 2000). Platelet activation is well known to occur in allergic inflammation, which could also be one of the mechanisms for the neural damage in AM and other atopy-related neural damage.

In the present study, we have revealed that $\mathrm{AM}$ is a progressive disease and that the platelet aggregative function is increased in AM. Thus, long-term use of an anti-platelet agent may be worth trying to prevent disease progression in this condition.

\section{Acknowledgments}

This work was supported in part by a Health and Labour Sciences Research Grant on Intractable Diseases (H22-Nanchi-Ippan-130) from the Ministry of Health, Labour and Welfare, Japan. 


\section{References}

Brunekreef, B., Hoek, G., Fischer, P., Spieksma, F.T., 2000. Relation between airborne pollen concentrations and daily cardiovascular and respiratory-disease mortality. Lancet 355, $1517-1518$.

Chapman, J., Vinokurov, S., Achiron, A., Karussis, D.M., Mitosek-Szewczyk, K., Birnbaum, M., Michaelson, D.M., Korczyn, A.D., 2001. APOE genotype is a major predictor of long-term progression of disability in MS. Neurology 56, 312-316.

Constantinescu, C.S., Thomas, M., Zaman, A.G., 2006. Atopic optic neuritis. Ocul. Immunol. Inflamm. 14, 125-127.

Faraday, N., Goldschmidt-Clermont, P.J., Bray, P., 1997. Gender differences in platelet GP IIb/IIIa activation. Thromb. Haemost. 77, 748-754.

Giorgi, D., Laganà, B., Giorgi, A., Verrasto, G., Grandinetti, F., Grandinetti, P.P., Gabrieli, C.B., 1997. Ischemic optic neuritis in Churg-Strauss syndrome. Recenti. Prog. Med. 88, 273-275.

Gregoire, S.M., Mormont, E., Laloux, P., Godfraind, C., Gilliard, C., 2006. Atopic myelitis: a clinical, biological, radiological and histopathological diagnosis. J. Neurol. Sci. 247, 231-235.

Hirayama, K., Toyokura, Y., Tsubaki, T., 1959. Juvenile muscular atrophy of unilateral upper 
extremity: a new clinical entity. Psychiatr. Neurol. Jpn. 61, 2190-2198.

Hirayama, K., Tomonaga, M., Kitano, K., Yamada, T., Kojima, S., Arai, K., 1987. Focal cervical poliopahy causing juvenile muscular atrophy of distal upper extremity: a pathological study. J. Neurol. Neurosurg. Psychiatry 50, 285-290.

Hirayama, K., 2000. Juvenile muscular atrophy of distal upper extremity. Intern. Med. 39, 283-290.

Hopkins, I.J., 1974. A new syndrome: poliomyelitis-like illness associated with acute asthma in childhood. Aust. Paediatr. J. 10, 273-276.

Isobe, N., Kira, J., Kawamura, N., Ishizu, T., Arimura, K., Kawano, Y., 2009. Neural damage associated with atopic diathesis. A nationwide surveys in Japan. Neurology 73, 790-797.

Ito, S., Kuwabara, S., Fukutake, T., Tokumaru, Y., Hattori, T., 2005. HyperIgEaemia in patients with juvenile muscular atrophy of the distal upper extremity (Hirayama disease). J. Neurol. Neurosurg. Psychiatry 76, 132-134.

Kasperska-Zajac, A., Rogala, B., 2007. Platelet activation during allergic inflammation. Inflammation 30, 161-166.

Kikuchi, H., Osoegawa, M., Ochi, H., Murai, H., Horiuchi, T., Takahashi, H., Yamabe, K., Iwaki, T., Mizutani, T., Oda, M., Kira, J., 2001. Spinal cord lesions of myelitis with 
hyperIgEemia and mite antigen specific IgE (atopic myelitis) manifest eosinophilic inflammation. J. Neurol. Sci. 183, 73-78.

Kira, J., Yamasaki, K., Kawano, Y., Kobayashi, T., 1997. Acute myelitis associated with hyperIgEemia and atopic dermatitis. J. Neurol. Sci. 148, 199-203.

Kira, J., Kawano, Y., Yamasaki, K., Tobimatsu, S., 1998. Acute myelitis with hyperIgEaemia and mite antigen specific IgE: atopic myelitis. J. Neurol. Neurosurg. Psychiatry 64, 676-679.

Kira, J., Kawano, Y., Horiuchi, I., Yamada, T., Imayama, S., Furue, M., Yamasaki, K., 1999. Clinical, immunological and MRI features of myelitis with atopic dermatitis (atopic myelitis). J. Neurol. Sci. 162, 56-61.

Kira, J., Horiuchi, I., Suzuki, J., Osoegawa, M., Tobimatsu, S., Murai, H., Minohara, M., Furue, M., Ochi, H., 2001. Myelitis associated with atopic disorders in Japan: a retrospective clinical study of the past 20 years. Intern. Med. 40, 613-619.

Kira, J., Ochi, H., 2001. Juvenile muscular atrophy of the distal upper limb (Hirayama disease) associated with atopy. J. Neurol. Neurosurg. Psychiatry. 70, 798-801.

Kira, J., Isobe, N., Kawano, Y., Osoegawa, M., Ohyagi, Y., Mihara, F., Murai, H., 2008. Atopic myelitis with focal amyotrophy: a possible link to Hopkins syndrome. J. Neurol. Sci. $269,143-151$. 
Kurtzke, J.F., 1983. Rating neurologic impairment in multiple sclerosis: an expanded disability status scale (EDSS). Neurology 33, 1444-1452.

Liou, H.H., Yip, P.K., Chang, Y.C., Liu, H.M., 1994. Allergic granulomatosis and angiitis (Churg-Strauss syndrome) presenting as prominent neurologic lesions and optic neuritis. J. Rheumatol. 21, 2380-2384.

Masini, E., Di Bello, M.G., Raspanti, S., Sacchi, T.B., Maggi, E., Mannaioni, P.F., 1994. Platelet aggregation and histamine release by immunological stimuli. Immunopharmacol. 28, $19-29$.

Matzdorff, A.C., Kühnel, G., Kemkes-Matthes, B., Voss, R., 2001. Comparison of GP IIB/IIIA inhibitors and their activity as measured by aggregometry, flow cytometry, single platelet counting, and the rapid platelet function analyzer. Journal of Thrombosis and Thrombolysis 12, 129-139

Michelson, A.D., 2009. Methods of the measurement of Platelet Function. Am. J. Cardiol. 103, 20A-26A.

Murai, H., Arahata, H., Osoegawa, M., Ochi, H., Minohara, M., Taniwaki, T., Tobimatsu, S., Mihara, F., Tsuruta, Y., Inaba, S., Kira, J., 2004. Effect of immunotherapy in myelitis with atopic diathesis. J. Neurol. Sci 227, 39-47.

Osoegawa, M., Ochi, H., Minohara, M., Murai, H., Umehara, F., Furuya, H., Yamada, T., 
Kira, J., 2003a. Myelitis with atopic diathesis: a nationwide survey of 79 cases in Japan. J. Neurol. Sci 209, 5-11.

Osoegawa, M., Ochi, H., Kikuchi, H., Shirabe, S., Nagashima, T., Tsumoto, T., Tamura, Y., Yamabe, K., Takahashi, H., Iwaki, T., Kira, J., 2003b. Eosinophilic myelitis associated with atopic diathesis: a combined neuroimaging and histopathological study. Acta Neuropathol. $105,289-295$.

Pitchford, S.C., 2007. Novel uses for anti-platelet agents as anti-inflammatory drugs. British Journal of Pharmacology 152, 987-1002.

Sanders, E.A., Bollen, E.L., van der Velde, E.A., 1986. Presenting signs and symptoms in multiple sclerosis. Acta Neurol. Scand. 73, 269-272.

Shahar, E.M., Hwang, P.A., Niesen, C.E., Murphy, E.G., 199. Poliomyelitis-like paralysis during recovery from acute bronchial asthma: possible etiology and risk factors. Pediatrics $88,276-279$.

Tanaka, M., Matsushita, T., Tateishi, T., Ochi, H., Kawano, Y., Mei, F-J., Minohara, M., Murai, H., Kira, J., 2008. Distinct CSF cytokine/chemokine profiles in atopic myelitis and other causes of myelitis. Neurology 71, 974-981.

Tokunaga, H., Osoegawa, M., Murai, H., Ochi, H., Minohohara, M., Taniwaki, T., Kira, J., 2004. Anterior horn cell involvement in myelitis with atopic diathesis (atopic myelitis). 
Fukuoka Igaku Zasshi 95, 36-43.

Van Werkum, J.W., Harmsze, A.M., Elsenberg, E.H., Bouman, H.J., Ten Berg, J.M., Hackeng, C.M., 2008. The use of the VerifyNow system to monitor antiplatelet therapy: A review of the current evidence. Platelets 19, 479-488.

Wheeler, G.L., Braden, G.A., Steinhubl, S.R., Kereiakes, D.J., Kottke-Marchant, K., Michelson, A.D., Furman, M.I., Mueller, M.N., Moliterno, D.J., Sane, S.C., 2002. The Ultegra rapid platelet-function assay: Comparison to standard platelet function assays in patients undergoing percutaneous coronary intervention with abciximab therapy. Am. Heart J. 143, 602-611.

White, M.M., Krishnan, R., Kueter, T.J., Jacoski, M.V., Jennings, L.K., 2004. The Use of the point of care Helena ICHOR/Plateletworks and the Accumetrics Ultegra RPFA for assessment of platelet function with GPIIb-IIIa antagonists. Journal of Thrombosis and Thrombolysis 18, 163-169.

Yakushkin, V.V., Zyuryaev, I.T., Khaspekova, S.G., Sirotkina, O.V., Ruda, M.Y., Mazurov, A.V., 2011. Glycoprotein IIb-IIIa content and platelet aggregation in healthy volunteers and patients with acute coronary syndrome. Platelets 22, 243-251.

Yoon, J.H., Joo, I.S., Li, W.Y., Sohn, S.Y., 2009. Clinical and laboratory characteristics of atopic myelitis: Korean experience. J. Neurol. Sci. 285, 154-158. 
Zoli, A., Mariano, M., Fusari, A., Bonifazi, F., Antonicelli, L., 2005. Atopic myelitis: first case report outside Japan? Allergy 60, 410-411. 
Table 1

Comparisons of the hematological and allergological findings between patients with atopic myelitis and healthy controls

\begin{tabular}{|c|c|c|c|}
\hline & $\begin{array}{l}\text { AM patients } \\
(\mathrm{n}=17)\end{array}$ & $\begin{array}{l}\text { Healthy controls } \\
(\mathrm{n}=35)\end{array}$ & $\mathrm{p}$ value ${ }^{\mathrm{a}}$ \\
\hline Bronchial asthma & $7(41.2 \%)$ & $1(2.9 \%)$ & $<0.001$ \\
\hline Atopic dermatitis & $5(29.4 \%)$ & $5(14.3 \%)$ & NS \\
\hline Allergic rhinitis & $10(58.8 \%)$ & $8(22.9 \%)$ & $<0.05$ \\
\hline Food Allergy & $6(35.3 \%)$ & $3(8.6 \%)$ & $<0.05$ \\
\hline Allergic conjunctivitis & $5(29.4 \%)$ & $2(5.7 \%)$ & $<0.05$ \\
\hline White blood cells $(/ \mu \mathrm{l})$ & $7174.7 \pm 2212.1$ & $6122.9 \pm 967.7$ & NS \\
\hline Neutrophils $(/ \mu 1)$ & $4570.7 \pm 1881.7$ & $3417.5 \pm 819.4$ & $<0.05$ \\
\hline Lymphocytes $(/ \mu 1)$ & $2010.2 \pm 747.1$ & $2088.3 \pm 358.4$ & NS \\
\hline Eosinophils $(/ \mu 1)$ & $235.0 \pm 173.6$ & $156.7 \pm 129.8$ & NS \\
\hline Platelets $(\times 10000 / \mu 1)$ & $24.8 \pm 5.3$ & $23.3 \pm 6.4$ & NS \\
\hline Hemoglobin (g/dl) & $13.0 \pm 1.5$ & $13.9 \pm 1.5$ & NS \\
\hline Total IgE (IU/ml) & $996.5 \pm 1619.2$ & $143.2 \pm 188.0$ & $<0.05$ \\
\hline Allergen specific IgE & & & \\
\hline $\begin{array}{l}\text { to Dermatophagoides } \\
\text { pteronyssinus }(\mathrm{UA} / \mathrm{ml})\end{array}$ & $24.6 \pm 37.0$ & $9.4 \pm 15.4$ & NS \\
\hline Allergen specific IgE & & & \\
\hline $\begin{array}{l}\text { to Dermatophagoides } \\
\text { farina }(\mathrm{UA} / \mathrm{ml})\end{array}$ & $23.6 \pm 34.6$ & $8.1 \pm 13.3$ & NS \\
\hline
\end{tabular}


Data are shown as means $\pm \mathrm{SD}$.

AM: atopic myelitis. NS: not significant. 
Gulibahaer Ainiding-20

\section{Figure legend}

Fig. 1. (A) Correlation between the disease duration and the EDSS scores in the AM patients.

(B) Correlation between the disease duration and the Sensory FS scores in the AM patients.

(C) Two-way ANOVA of the GP IIb/IIIa values by sex and disease. The GP IIb/IIIa levels are significantly higher in females than in males and in the AM patients compared with the controls. (D) Correlation between the GP IIb/IIIa values and the platelet counts in the AM patients and controls. (E) Correlation between the GP IIb/IIIa values and the hemoglobin concentrations in the AM patients and controls. AM: atopic myelitis. 
A

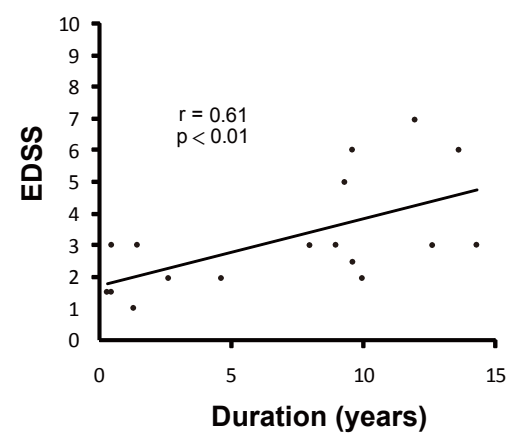

C

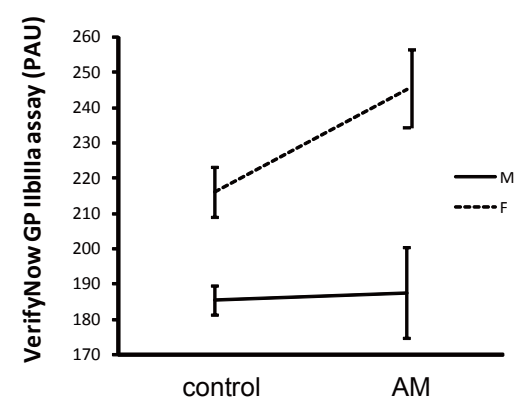

D

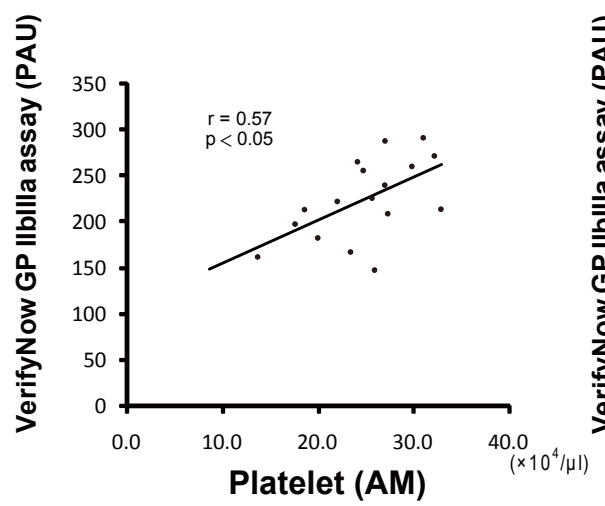

E

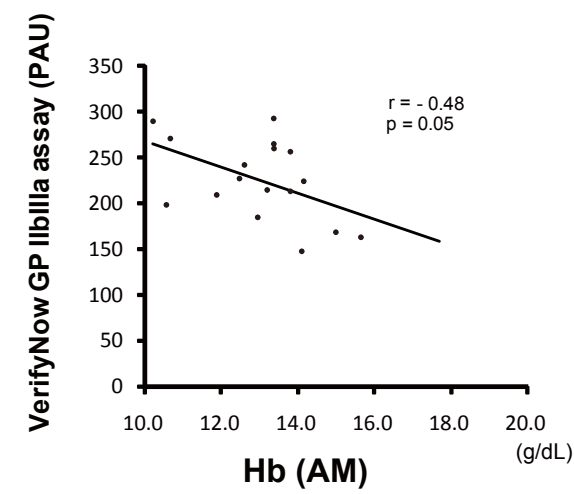

B

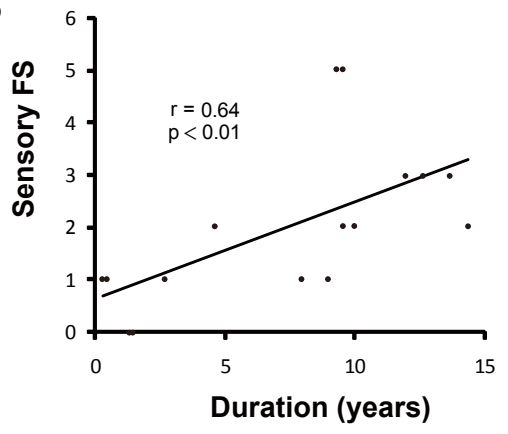

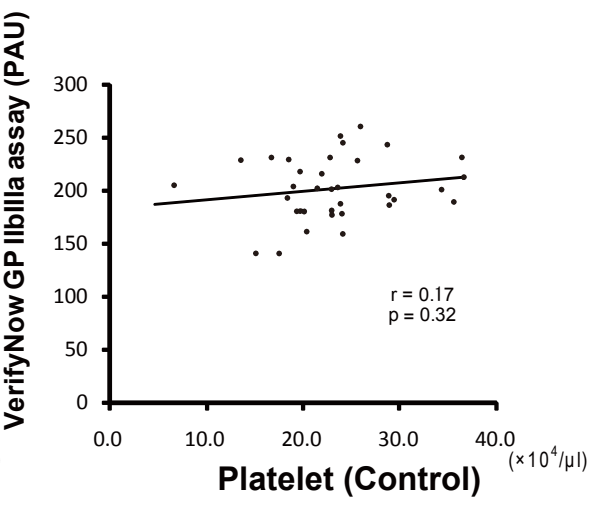

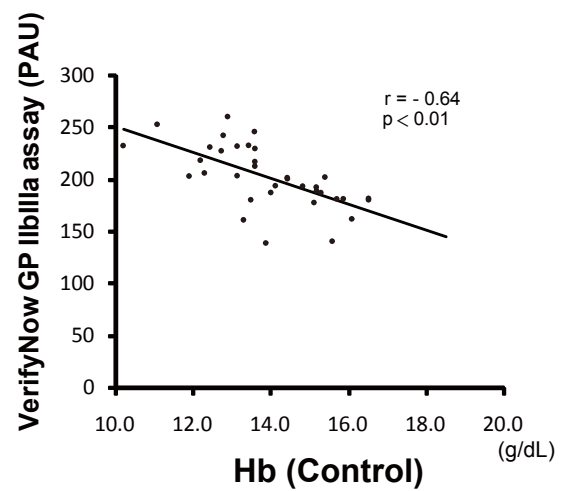

